\title{
Stearic Acid Serves as a Potent Inhibitor of Protein Tyrosine Phosphatase 1B
}

\author{
Ayako Tsuchiya Takeshi Kanno Tomoyuki Nishizaki \\ Division of Bioinformation, Department of Physiology, Hyogo College of Medicine, \\ Nishinomiya, Japan
}

\section{Key Words}

Stearic acid • Protein tyrosine phosphatase 1B • Insulin receptor • Akt • Glucose uptake

\begin{abstract}
Background/Aims: Free fatty acids (FFAs) are implicated in diverse signal transduction pathways. The present study investigated the effects of the saturated FFA stearic acid on protein tyrosine phosphatase 1B (PTP1B) activity, Akt activity, and glucose uptake into cells relevant to insulin signal. Methods: PTP1B activity was assayed under the cell-free conditions. Phosphorylation of insulin receptor and Akt and glucose uptake into cells were monitored in differentiated 3T3-L1-GLUT4myc adipocytes. Results: In the cell-free PTP1B assay, stearic acid suppressed PTP1B activity in a concentration (1-30 $\mu \mathrm{M})$-dependent manner. For 3T3-L1GLUT4myc adipocytes insulin phosphorylated insulin receptor at Tyr1185 and Akt at Thr308 and Ser473 in a concentration (100 fM-100 nM)-dependent manner and stimulated glucose uptake into cells in a concentration (0.1-100 nM)-dependent manner. Stearic acid (30 $\mu \mathrm{M})$ significantly increased insulin-induced phosphorylation of insulin receptor at Tyr1185, but insulin-induced phosphorylation of Akt was not significantly enhanced. Stearic acid ( $30 \mu \mathrm{M})$ by itself promoted glucose uptake into adipocytes. Conclusion: The results of the present study indicate that stearic acid serves as a potent PTP1B inhibitor, possibly causing an enhancement in the insulin receptor signaling to stimulate glucose uptake into adipocytes.
\end{abstract}

Copyright $\odot 2013$ S. Karger AG, Basel

\section{Introduction}

Insulin stimulates GLUT4-mediated glucose uptake into cells through a pathway along an insulin receptor/insulin receptor substrate (IRS)/phosphatidylinositol 3 kinase (PI3K)/3-phosphoinositide-dependent protein kinase-1 (PDK1)/Akt axis, and Akt plays a 
pivotal role in the regulation of GLUT4 translocation to the cell surface. Insulin receptor is a member of the receptor tyrosine kinase (RTK) family, and insulin initiates insulin signaling by phosphorylating its own receptor and IRS-1.

Excess free fatty acids (FFAs) in skeletal muscle cells, liver cells, and adipocytes may attenuate insulin signaling by inhibiting insulin-induced Akt activation or upregulating protein tyrosine phosphatase 1B (PTP1B), a negative regulator of insulin signaling [1]. Saturated FFAs such as palmitic and stearic acid at a considerably high concentration of 200 $\mu \mathrm{M}$ are shown to upregulate expression of the PTP1B mRNA and enhance PTP1B activity [1, 2]. Palmitic acid also reduces insulin-induced phosphorylation of Akt at Thr308 and Ser473 in L6 skeletal muscle cells, without affecting expression or activity of PI3K, and suppresses insulin-stimulated glucose uptake in C2C12 myotubes [2, 3]. Amazingly, short-tem (15 min) treatment with saturated free fatty acids at $1 \mathrm{mM}$ promoted glucose uptake into rat adipocytes, but conversely long-term treatment inhibits insulin-stimulated glucose uptake [4]. Collectively, these results suggest that saturated FFAs could be a factor responsible for insulin resistance related to type 2 diabetes.

Palmitic acid reduces glucose uptake by inhibiting phosphorylation of Src at Tyr416 and Src-mediated phosphorylation of Akt at Thr308 and Ser473 in C2C12 myotubes [3]. Ceramide is known to activate serine/threonine protein phosphatases such as protein phosphatase 1 (PP1) and protein phosphatase 2A (PP2A), causing Akt inhibition through its dephosphorylation [5, 6]. Saturated FFAs accumulate ceramide in skeletal muscle cells, to dephosphorylate and inactivate Akt, causing decrease in the glucose uptake into cells [6]. Accumulating evidence has pointed to association between an increase in diacylglycerol (DAG) content and insulin resistance in the muscle and liver [7, 8]. Protein kinase C\& (PKCE) activated by DAG inhibits tyrosine kinase activity of insulin receptor through its Ser/Thr phosphorylation [9]. Palmitic acid at 1 mM markedly increases the amount of DAG and PKCE in HepG2 cells [10]. Saturated FFAs, thus, appear to cause insulin resistance in the skeletal muscle and liver. Little, however, is known about saturated FFA-induced insulin resistance in adipocytes.

To address this question, the present study investigated the effect of stearic acid, a saturated FFA, on PTP1B activity, Akt activity, and glucose uptake into cells relevant to insulin signal. The results show that stearic acid suppresses PTP1B activity, which may enhance insulin receptor signaling and stimulate glucose uptake into 3T3-L1-GLUT4myc adipocytes. This may provide fresh insight into the role of stearic acid as a PTP1B inhibitor relevant to insulin receptor signaling.

\section{Materials and Methods}

\section{Cell-free PTP1B assay}

PTP1B activity under the cell-free conditions was assayed by the method as previously described [11]. The human PTP1B was cloned into pGEX-6P-3 vector with a GST tag at the $\mathrm{NH}_{2}$ terminus, and expressed in competent E. coli BL21 (DE3), suitable for transformation and protein expression. GST-fusion PTP1B was affinity-purified using Glutathione Sepharose 4B (GE Healthcare Bio-Science KK, Tokyo, Japan). PTP1B activity was assayed by reacting with $p$-nitrophenyl phosphate (pNPP)(Sigma, St. Louis, MO, USA) as a substrate. PTP1B (1 $\mu \mathrm{g} /$ well) was preincubated in a reaction medium (50 mM HEPES, $1 \mathrm{mM}$ EDTA, $50 \mathrm{mM}$ $\mathrm{NaCl}, 1 \mathrm{mM}$ dithiothreitol, $\mathrm{pH}$ 7.2) in the presence and absence of sodium orthovanadate or stearic acid at $37^{\circ} \mathrm{C}$ for $30 \mathrm{~min}$. Then, pNPP (10 mM) was added to the reaction medium followed by 60 -min incubation, and the reaction was terminated by adding $0.1 \mathrm{~N} \mathrm{NaOH}$. Dephosphorylated pNPP was quantified at an absorbance of $405 \mathrm{~nm}$ with a SpectraMax PLUS384 (Molecular Devices, Sunnyvale, CA, USA).

\section{Cell culture}

3T3-L1-GLUT4myc fibroblast cell line, expressing GLUT4myc that is constructed by inserting a human c-MYC epitope (14 amino acids) into the first ectodomain of GLUT4. Cells were cultured in Dulbecco's modified Eagle's medium (DMEM) supplemented with $10 \%(\mathrm{v} / \mathrm{v})$ calf serum, penicillin (final concentration, 
$100 \mathrm{U} / \mathrm{ml}$ ), and streptomycin (final concentration, $0.1 \mathrm{mg} / \mathrm{ml}$ ), in a humidified atmosphere of $5 \% \mathrm{CO}_{2}$ and $95 \%$ air at $37^{\circ} \mathrm{C}$. When cells had reached confluence (day 0), medium was changed to DMEM supplemented with $10 \%(\mathrm{v} / \mathrm{v}$ ) fetal bovine serum (FBS), $1 \mu \mathrm{M}$ dexamethasone, $0.5 \mathrm{mM}$ 3-isobutyl-methyl-xanthine and $0.1 \mathrm{mg} / \mathrm{ml}$ insulin to differentiate from fibroblast to adipocytes (3T3-L1-GLUT4myc adipocytes). At day 3, day 7 and day 11, the medium was changed to DMEM supplemented with $10 \%$ (v/v) FBS. At 14 day, cells were used for experiments.

\section{Western blotting}

3T3-L1-GLUT4myc adipocytes were incubated in Krebs-Ringer-HEPES buffer (136 mM NaCl, $4.7 \mathrm{mM}$ $\mathrm{KCl}, 1.25 \mathrm{mM} \mathrm{CaCl}_{2}, 1.25 \mathrm{mM} \mathrm{MgSO}_{4}$ and $20 \mathrm{mM}$ HEPES, pH 7.5) containing $0.2 \%(\mathrm{w} / \mathrm{v}$ ) bovine serum albumin (BSA) supplemented with $10 \mathrm{mM}$ glucose for $1 \mathrm{~h}$ at $37^{\circ} \mathrm{C}$. Cells treated with and without insulin in the presence and absence of stearic acid for 1-20 min were lysed in a lysis buffer [150 $\mathrm{mM} \mathrm{NaCl}, 20 \mathrm{mM}$ EDTA, $0.5 \%$ (v/v) Nonidet P-40 and $50 \mathrm{mM}$ Tris, $\mathrm{pH} 7.4$ ] containing $1 \%(\mathrm{v} / \mathrm{v}$ ) protease inhibitor cocktail and $1 \%(\mathrm{v} / \mathrm{v})$ phosphatase inhibitor cocktail (Nacalai Tesque, Kyoto, Japan), and then centrifuged at 3,000 rpm for $5 \mathrm{~min}$ at $4{ }^{\circ} \mathrm{C}$. The supernatant was used as total cell lysate. Protein concentrations for each sample were determined with a BCA protein assay kit (Thermo Fisher Scientific, Waltham, MA, USA).

Proteins were separated by sodium dodecyl sulfate-polyacrylamide gel electrophoresis (SDS-PAGE) and then transferred to polyvinylidene difluoride (PVDF) membranes. Blotting membranes were blocked with TBS-T containing $5 \%(\mathrm{w} / \mathrm{v})$ BSA and subsequently reacted with antibodies against phospho-Tyr1185insulin receptor $\beta$ subunit (pY1185)(Bioss, Inc., Wobum, MA, USA), insulin receptor $\beta$-subunit (IR)(Thermo Fisher Scientific), phospho-Tyr1222-IRS-1 (pY1222)(Cell Signaling Technology, Inc., Danvers, MA, USA), IRS-1 (Santa Cruz Biotechnology, Inc., Dallas, Texas, USA), phospho-Thr308-Akt (pT308)(Cell Signaling Technology), phospho-Ser473-Akt (pS473)(Cell Signaling Technology, Inc.), and Akt (Cell Signaling Technology, Inc.). After washing, membranes were reacted with a horseradish peroxidase-conjugated goat anti-rabbit IgG antibody or goat anti-mouse IgG antibody. Immunoreactivity was detected with an ECL kit (Invitrogen, Carlsbad, CA, USA) and visualized using a chemiluminescence detection system (GE Healthcare, Piscataway, NJ, USA). Signal density was measured with an Image Gauge software (GE Healthcare).

Glucose uptake assay

3T3-L1-GLUT4myc adipocytes were incubated in the Krebs-Ringer-HEPES buffer containing $0.2 \%$ $(\mathrm{w} / \mathrm{v})$ BSA supplemented with $10 \mathrm{mM}$ glucose for $1 \mathrm{~h}$ at $37^{\circ} \mathrm{C}$. Then, cells were untreated and treated with insulin and/or stearic acid in phosphate-buffered saline (PBS) supplemented with $10 \mathrm{mM}$ glucose for $2 \mathrm{~h}$ at 37 ${ }^{\circ} \mathrm{C}$. After treatment, extracellular solution was collected and glucose was labeled with $p$-aminobenzoic ethyl ester (ABEE). Then, $5 \mu \mathrm{l}$ of ABEE-labeled solution was injected onto the column (150 X $4.6 \mathrm{~mm}$ ) equipped in the high performance liquid chromatography (HPLC) system. ABEE-labeled glucose was detected at an excitation wavelength of $305 \mathrm{~nm}$ and an emission wavelength of $360 \mathrm{~nm}$ using a fluorescence detector. Glucose concentration taken up into cells was calculated by subtracting extracellular glucose concentration after 2-h incubation from initial extracellular glucose concentration (10 mM).

Stearic acid

Stearic acid was dissolved with dimethyl sulfoxide (DMSO) and stocked. Stocked stearic acid was diluted at more than 1000-fold with the reaction medium or extracellular solution in usage for experiments.

Statistical analysis

Statistical analysis was carried out using Dunnett's test and analysis of variance (ANOVA) followed by a Bonferonni correction.

\section{Results}

Stearic acid attenuated PTP1B activity

In the PTP1B assay, sodium orthovanadate $\left(\mathrm{Na}_{3} \mathrm{VO}_{4}\right)(1 \mu \mathrm{M})$, an inhibitor of PTP1B, significantly suppressed PTP1B activity (Fig. 1), confirming a reliable PTP1B assay. Stearic acid reduced PTP1B activity in a concentration (1-30 $\mu \mathrm{M})$-dependent manner, the extent 
Fig. 1. Effect of stearic acid on PTP1B activity. PTP1B was reacted with pNPP in the presence and absence of $\mathrm{Na}_{3} \mathrm{VO}_{4}(1 \mu \mathrm{M})$ or stearic acid at concentrations as indicated, and dephosphorylated pNPP was quantified. In the graph, each value represents the mean ( \pm SEM) percentage of basal phosphatase activity (Control)( $\mathrm{n}=4$ independent experiments). ${ }^{* * *} P<0.0001$ as compared with control, Dunnett's test.

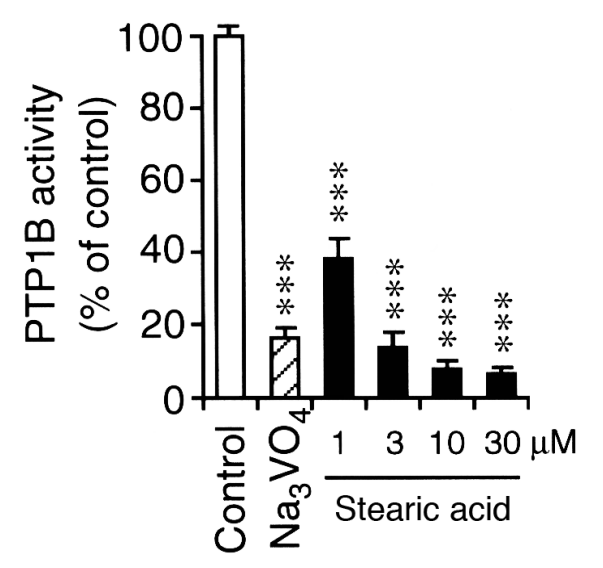

Fig. 2. The insulin concentration/phosphorylation of insulin receptor and Akt relations. 3T3-L1GLUT4myc adipocytes were untreated and treated with insulin at concentrations as indicated for $10 \mathrm{~min}$. Western blotting was carried out using antibodies against pY1185 and insulin receptor (IR) (A) or pT308, pS473, and Akt (B). Signal intensities for phosphorylated IR and Akt were normalized by those for total IR and Akt, respectively. In the graphs, each column represents the mean ( \pm SEM) normalized intensity for pY1185, pT308, and pS473 ( $n=4$ independent experiments).
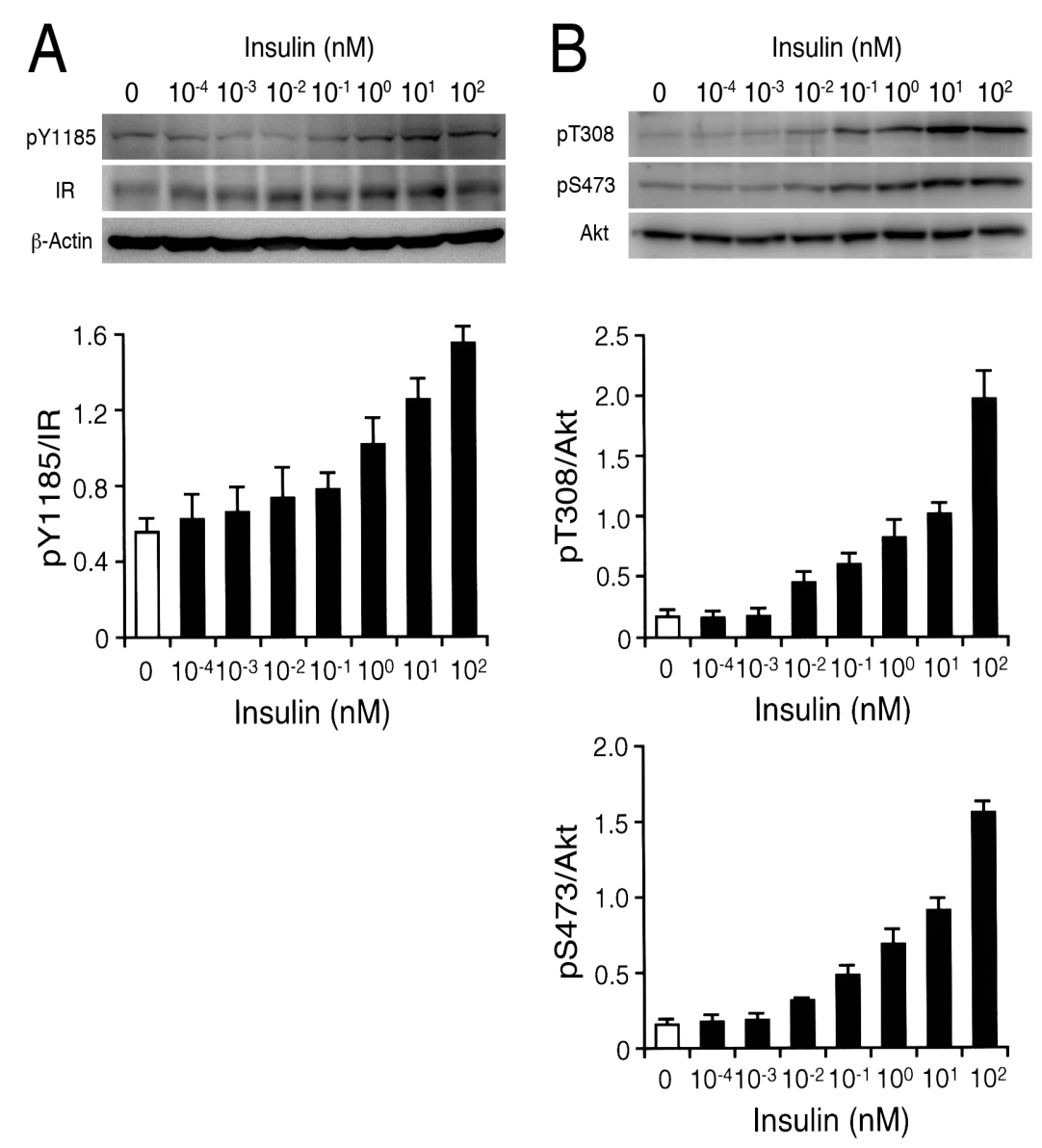

reaching $8 \%$ of basal levels at $30 \mu \mathrm{M}$ (Fig. 1). This suggests that stearic acid serves as a PTP1B inhibitor. PTP1B dephosphorylates tyrosine phosphorylation, and therefore, inhibition of PTP1B maintains tyrosine phosphorylation. Then, we postulated that stearic acid might enhance an insulin signal transduction pathway through a persistent tyrosine phosphorylation of insulin receptor and IRS due to PTP1B inhibition. 
Fig. 3. The insulin treatment time/phosphorylation of IRS1 and Akt relations. 3 T 3 - L 1 - G LU T 4 m y c adipocytes were untreated and treated with insulin (100 nM) for periods of time as indicated. Western blotting was carried out using antibodies against pY1222 and IRS-1 (A) or pT308, pS473, and Akt (B). Signal intensities for phosphorylated IRS-1 and Akt were normalized by those for total IRS-1 and Akt, respectively. In the graphs, each column represents the mean ( \pm SEM) normalized intensity for pY1222, pT308, and pS473 (n=4 independent experiments).

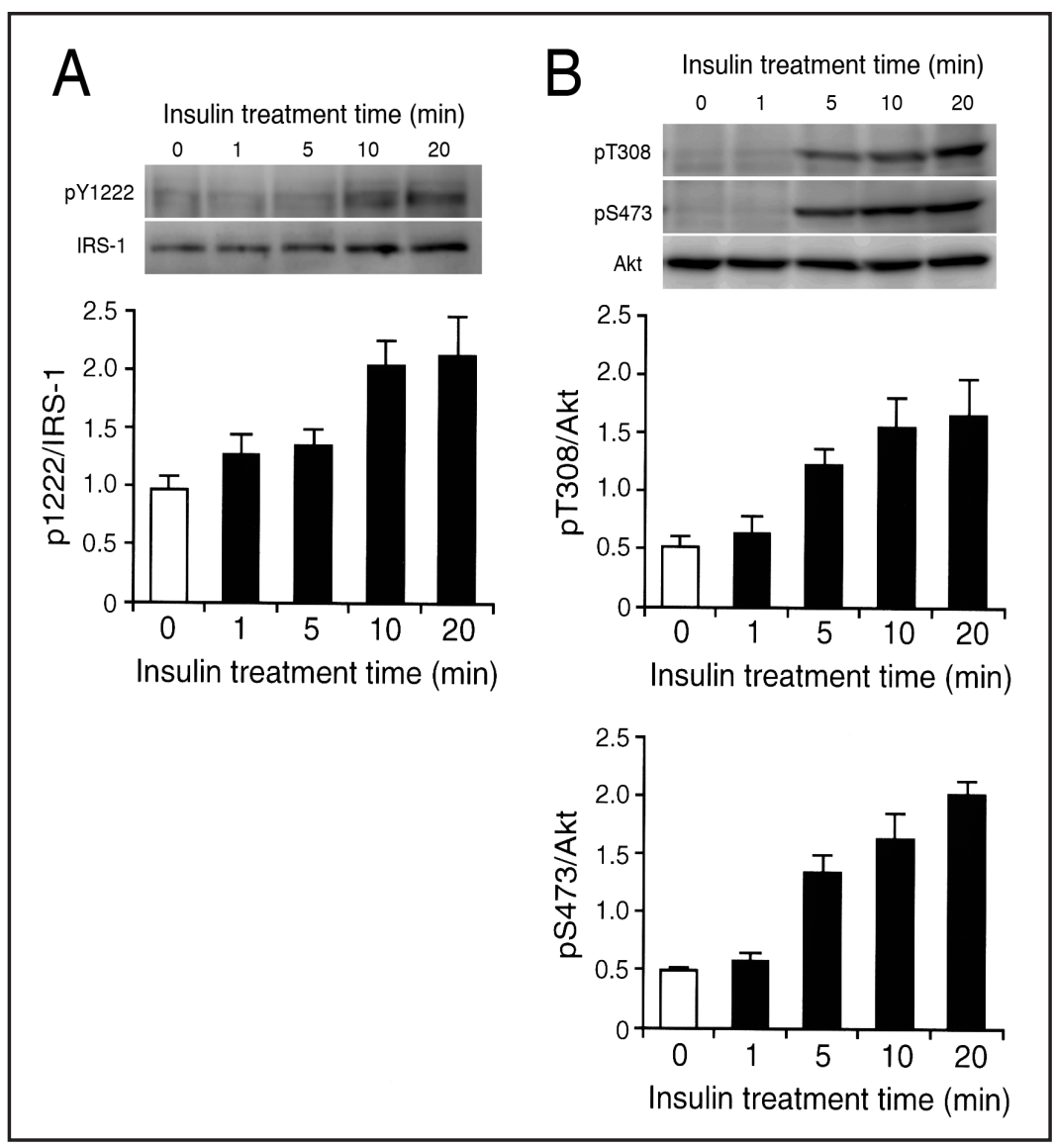

Insulin phosphorylates insulin receptor at Tyr1185, IRS-1 at Y1222, and Akt at Thr308 and Ser473 in a concentration- and treatment-time dependent manner

In our earlier study, we have confirmed that 3T3-L1-GLUT4myc fibroblasts are well differentiated into adipocytes using Oil-Red 0 , to detect adipose conversion. Insulin stimulates glucose uptake into adipocytes and skeletal muscles to reduce serum glucose levels by delivering the glucose transporter GLUT4 to the cell surface from the cytosol through a pathway along an insulin receptor/IRS/PI3K/PDK1/Akt axis. In the present study, insulin increased phosphorylation of insulin receptor at Tyr1185 in a concentration (100 fM-100 nM)-dependent manner in 3T3-L1-GLUT4myc adipocytes (Fig. 2A). This indicates that when activated insulin receptor phosphorylates its own receptor. Insulin, alternatively, phosphorylated Akt both at Thr308 and Ser473 in a concentration (100 fM-100 nM)dependent manner in 3T3-L1-GLUT4myc adipocytes (Fig. 2B).

Insulin (100 nM) phosphorylated IRS-1 at Tyr1222 in a treatment time (1-20 min)dependent manner in 3T3-L1-GLUT4myc adipocytes (Fig. 3A). Moreover, Insulin (100 nM) phosphorylated Akt both at Thr308 and Ser473 in a treatment time (1-20 min)-dependent manner in 3T3-L1-GLUT4myc adipocytes (Fig. 3B).

\section{Stearic acid enhances insulin receptor signaling}

In the cell-free PTP1B assay, the maximal inhibitory effect of stearic acid on PTP1B activity was obtained at $30 \mu \mathrm{M}$. To examine how stearic acid affects insulin signal and glucose uptake into 3T3-L1-GLUT4myc adipocytes, we therefore used stearic acid of $30 \mu \mathrm{M}$ for all the ensuing experiments. To examine the effect of stearic acid on phosphorylation of insulin receptor and Akt, we chose insulin treatment time of $10 \mathrm{~min}$ from the data of the insulin treatment time/phosphorylation of IRS-1 or Akt relation. Stearic acid (30 $\mu \mathrm{M})$ significantly increased insulin (0.1 nM)-induced phosphorylation of insulin receptor at Tyr1185 in 3T3L1-GLUT4myc adipocytes, although basal tyrosine phosphorylation of the receptor was 
Fig. 4. Effect of stearic acid on phosphorylation of insulin receptor and Akt. 3T3-L1GLUT4myc adipocytes were untreated and treated with insulin (Ins)(0.1 nM) and/ or stearic acid $(\mathrm{SA})(30 \mu \mathrm{M})$ for $10 \mathrm{~min}$, followed by Western blotting using antibodies against pY1185 and insulin receptor (IR) (A) or pT308, pS473, and Akt (B). Signal intensities for phosphorylated IR and Akt were normalized by those for total IR and Akt, respectively. In the graphs, each column represents the mean $( \pm$ SEM) normalized intensity for pY1185, pT308, and pS473 $(\mathrm{n}=4$ independent experiments). $P$ values, ANOVA followed by a Bonferonni correction. $N S$, not significant.
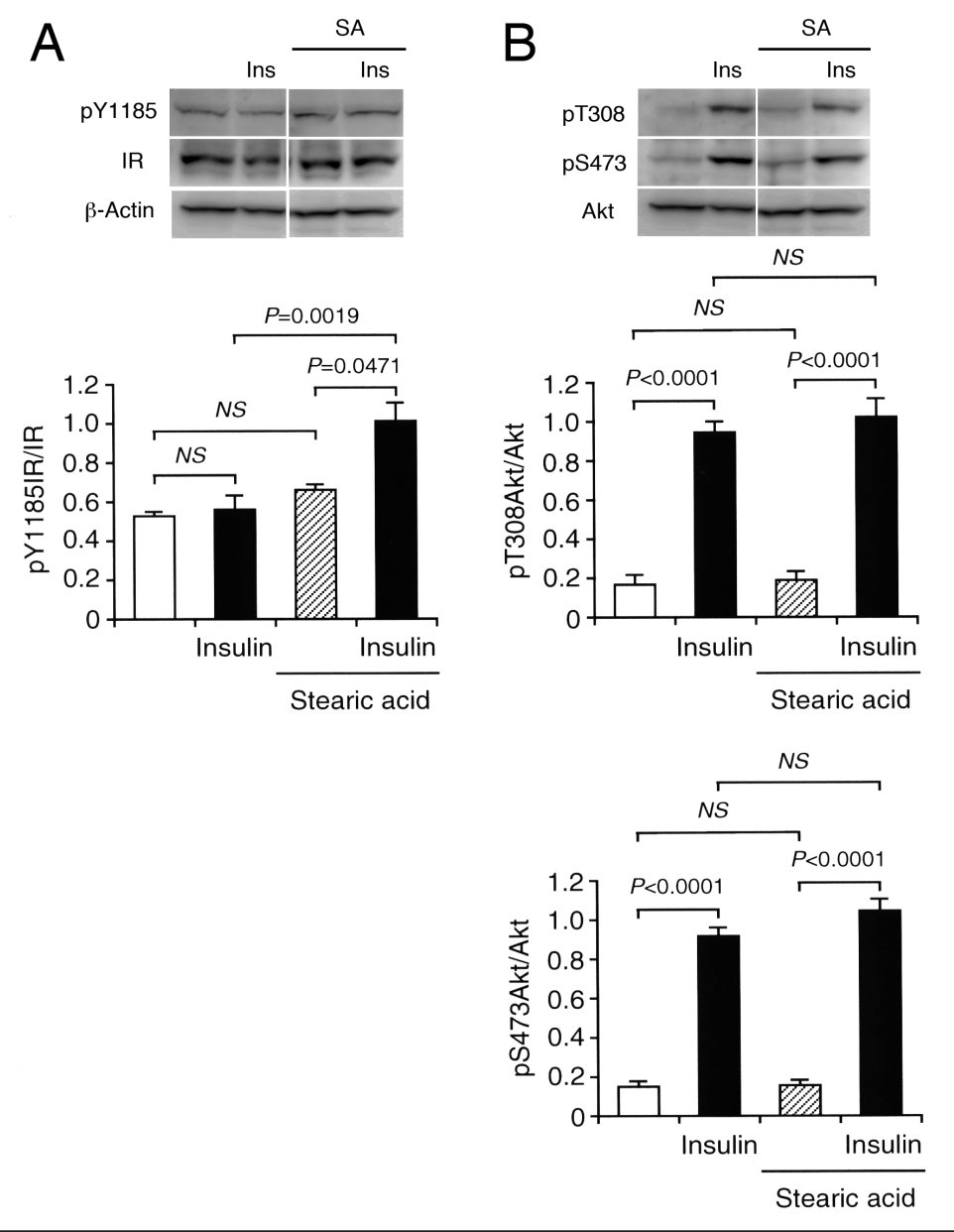

Fig. 5. Effect of insulin and/ or stearic acid on glucose uptake into 3T3-L1-GLUT4myc adipocytes. (A) Adipocytes were incubated in PBS containing glucose $(10 \mathrm{mM})$ for $2 \mathrm{~h}$ in the presence and absence of insulin at concentrations as indicated, and then extracellular glucose was measured by HPLC. In the graph, each column represents the mean \pm SEM) glucose uptake (nmol/ $\mu \mathrm{g}$ protein/min)(n=4 independent experiments). $P$ values,

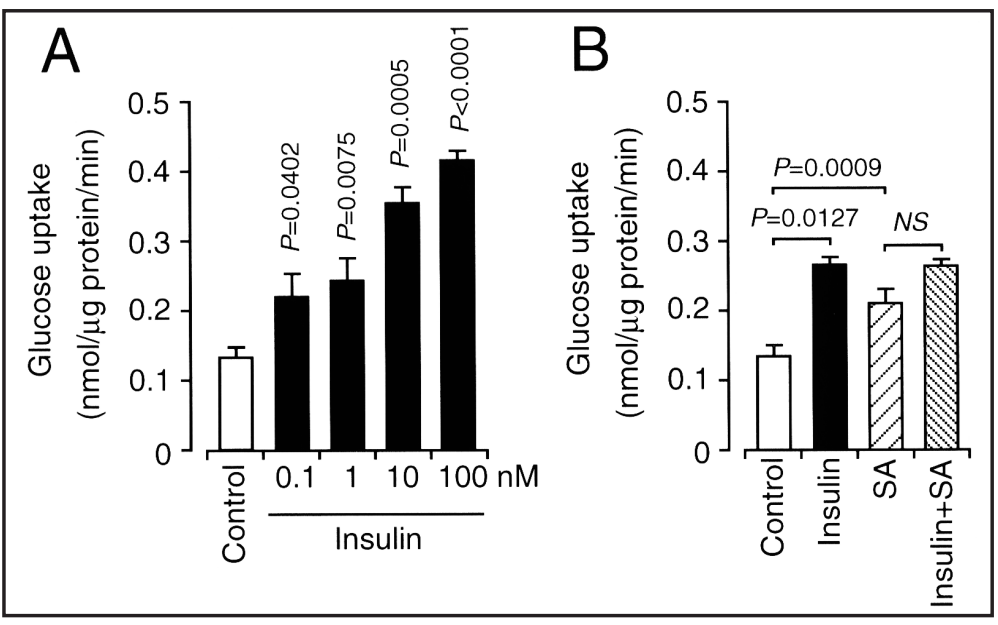

Dunnett's test. (B) Adipocytes were incubated in PBS containing glucose (10 mM) for $2 \mathrm{~h}$ in the presence and absence of insulin $(0.1 \mathrm{nM})$ and/or stearic acid $(\mathrm{SA})(30 \mu \mathrm{M})$, and then extracellular glucose was measured by HPLC. In the graph, each column represents the mean $( \pm \mathrm{SEM})$ glucose uptake (nmol/ $\mu \mathrm{g}$ protein/ $\min )(\mathrm{n}=4$ independent experiments). $P$ values, Dunnett's test. $N S$, not significant.

not significantly enhanced (Fig. 4A). This suggests that stearic acid could enhance insulin/ insulin receptor signaling. In contrast, stearic acid $(30 \mu \mathrm{M})$ induced no significant increase in the basal and insulin (0.1 nM)-induced phosphorylation of Akt at Thr308 and Ser473 (Fig. 
4B). This suggests that the allosteric effect of stearic acid on insulin-induced Akt activation is very modest, although the acid has the potential to enhance insulin/insulin receptor signaling.

Stearic acid promotes glucose uptake into cells

We finally examined the effect of stearic acid on glucose uptake into 3T3-L1-GLUT4myc adipocytes. Insulin stimulated glucose uptake into 3T3-L1-GLUT4myc adipocytes in a concentration (0.1-100 $\mathrm{nM}$ )-dependent manner, the extent reaching 3-folds of control levels at $100 \mathrm{nM}$ (Fig. 5A). Stearic acid (30 $\mu \mathrm{M})$ significantly increased glucose uptake into 3T3L1-GLUT4myc adipocytes to 2-folds of control levels still in the absence of insulin, but the acid did not additionally increase insulin $(0.1 \mathrm{nM})$-stimulated glucose uptake into cells (Fig. 5B). Taken together, these results suggest that stearic acid promotes glucose uptake into adipocytes by stimulating insulin/insulin receptor signaling in association with PTP1B inhibition, but that the acid has no allosteric effect on insulin-stimulated glucose uptake.

\section{Discussion}

RTK including insulin receptor is linked to a signal transduction pathway along an RTK/IRS/PI3K/PDK1/Akt axis [12, 13]. Activated RTK phosphorylates RTK and IRS at the tyrosine residue, to dissociate IRS from the receptor and activate PI3K. Activated PI3K produces phosphatidylinositol $(3,4,5)$-triphosphate $\left[\mathrm{PI}(3,4,5) \mathrm{P}_{3}\right]$ by phosphorylating phosphatidylinositol 4,5-bisphosphate $\left[\mathrm{PI}(4,5) \mathrm{P}_{2}\right]$, and in turn, $\mathrm{PI}(3,4,5) \mathrm{P}_{3}$ activates PDK1 through its binding. Activated PDK1 activates Akt by phosphorylating at Thr308 and Ser473 for Akt.

Of particular interest in the present study is the finding that the saturated FFA stearic acid markedly reduced PTP1B activity. To our knowledge, this is the first providing evidence for stearic acid as a potential inhibitor of PTP1B. How stearic acid inhibits PTP1B, however, is far from understanding. We obtained evidence that the linoleic acid derivative DCP-LA suppresses PTP1B activity and directly binds to PTP1B (unpublished data). This raises the possibility that stearic acid might inhibit PTP1B through its direct binding.

PTP1B functions as a negative regulator of insulin receptor signaling pathways by dephosphorylating the receptor [14-16]. Stearic acid, accordingly, could enhance insulin/ insulin receptor signaling by preventing tyrosine dephosphorylation of insulin receptor and IRS-1 due to PTP1B inhibition. In support of this, stearic acid significantly increased insulininduced phosphorylation of insulin receptor at Tyr1185 in 3T3-L1-GLUT4myc adipocytes and not significantly increased basal tyrosine phosphorylation of the receptor. Stearic acid also increased basal and insulin-induced phosphorylation of Akt at Thr308 and Ser473, but not significantly. Overall, these results indicate that stearic acid enhances insulin/ insulin receptor signaling by suppressing tyrosine dephosphorylation of insulin receptor in association with PTP1B inhibition, even though stearic acid is not capable of inducing full activation of Akt.

Insulin stimulated glucose uptake into 3T3-L1-GLUT4myc adipocytes in a concentration (0.1-100 nM)-dependent manner. Amazingly, stearic acid stimulated glucose uptake into cells still in the absence of insulin, although the acid induced no additional increase in insulinstimulated glucose uptake. Overall, the results of the present study lead to a conclusion that the saturated FFA stearic acid has the potential to inhibit PTP1B, possibly causing an enhancement in the insulin receptor signaling by preventing tyrosine dephosphorylation of the receptor to stimulate glucose uptake into adipocytes.

The facilitatory effect of stearic acid on glucose uptake into adipocytes interprets that stearic acid might protect from insulin resistance. In support of this note, short-term (15 $\mathrm{min}$ ) treatment with stearic acid or palmitic acid is shown to stimulate glucose uptake into adipocytes [4]. In contrast, long-term ( $4 \mathrm{~h}$ ) treatment with palmitic acid exhibits a contrary effect, i.e., inhibition of glucose uptake [4]. The data of glucose assay here was obtained from 
2 h-treatment with stearic acid at a concentration of $30 \mu \mathrm{M}$. In addition, we have confirmed that glucose uptake is not significantly inhibited still by 4 -h treatment with stearic acid. Most of previous studies have pointed that saturated FFAs induce or accelerate insulin resistance related to type 2 diabetes [4, 17-22]. It is presently unknown why saturated FFAs exhibit bidirectional effects on glucose uptake. This might be due to difference in the concentrations used. In the studies to support saturated FFA-induced insulin resistance, saturated FFAs were used at extremely higher concentrations ranging from 0.125 to $2 \mathrm{mM}$ as compared with those used here (1-30 $\mu \mathrm{M})$ [1-4]. To address this question, we are currently carrying out further experiments.

In conclusion, the results of the present study show that the saturated FFA stearic acid serves as a potent inhibitor of PTP1B, which may enhance insulin receptor signaling by preventing tyrosine dephosphorylation of the receptor and stimulate glucose uptake into adipocytes. This may extend our understanding about saturated FFA signaling linked to diabetes type 2 .

\section{Acknowledgements}

We thank to Prof. Ebina (Institute for Enzyme Research, The University of Tokushima, Tokushima, Japan) for providing us with a 3T3-L1-GLUT4myc fibroblast cell line.

\section{References}

1 Obanda DN, Cefalu WT: Modulation of cellular insulin signaling and PTP1B effects by lipid metabolites in skeletal muscle cells. J Nutr Biochem 2013;24:1529-1537.

2 Obanda DN, Hernandez A, Ribnicky D, Yu Y, Zhang XH, Wang ZQ, Cefalu WT: Bioactives of Artemisia dracunculus L. mitigate the role of ceramides in attenuating insulin signaling in rat skeletal muscle cells. Diabetes 2012;61:597-605.

-3 Feng XT, Wang TZ, Leng J, Chen Y, Liu JB, Liu Y, Wang WJ: Palmitate contributes to insulin resistance through downregulation of the Src-mediated phosphorylation of Akt in C2C12 myotubes. Biosci Biotechnol Biochem 2012;76:1356-1361.

4 Hunnicutt JW, Hardy RW, Williford J, McDonald JM: Saturated fatty acid-induced insulin resistance in rat adipocytes. Diabetes 1994;43:540-545.

-5 Chalfant CE, Kishikawa K, Mumby MC, Kamibayashi C, Bielawska A, Hannun YA: Long chain ceramides activate protein phosphatase-1 and protein phosphatase-2A. Activation is stereospecific and regulated by phosphatidic acid. J Biol Chem 1999;274:20313-20317.

-6 Wolff RA, Dobrowsky RT, Bielawska A, Obeid LM, Hannun YA: Role of ceramide-activated protein phosphatase in ceramide-mediated signal transduction. J Biol Chem 1994;269:19605-19609.

7 Montell E, Turini M, Marotta M, Roberts M, Noé V, Ciudad CJ, Macé K, Gómez-Foix AM: DAG accumulation from saturated fatty acids desensitizes insulin stimulation of glucose uptake in muscle cells. Am J Physiol Endocrinol Metab 2001;280:E229-237.

8 Watson ML, Coghlan M, Hundal HS: Modulating serine palmitoyl transferase (SPT) expression and activity unveils a crucial role in lipid-induced insulin resistance in rat skeletal muscle cells. Biochem J 2009;417:791-801.

9 Samuel VT, Liu ZX, Wang A, Beddow SA, Geisler JG, Kahn M, Zhang XM, Monia BP, Bhanot S, Shulman GI: Inhibition of protein kinase $\mathrm{C} \varepsilon$ prevents hepatic insulin resistance in nonalcoholic fatty liver disease. J Clin Invest 2007;117:739-745.

10 Lee JY, Cho HK, Kwon YH: Palmitate induces insulin resistance without significant intracellular triglyceride accumulation in HepG2 cells. Metabolism 2010;59:927-934.

- 11 Kanno T, Tsuchiya A, Shimizu T, Tanaka A, Nishizaki T: Indomethacin serves as a potential inhibitor of protein phosphatases. Cell Physiol Biochem 2012;30:1014-1022. 
12 Niba ET, Nagaya H, Kanno T, Tsuchiya A, Gotoh A, Tabata C, Kuribayashi K, Nakano T, Nishizaki T: Crosstalk between PI3 kinase/PDK1/Akt/Rac1 and Ras/Raf/MEK/ERK pathways downstream PDGF receptor. Cell Physiol Biochem 2013;31:905-913.

13 Claesson-Welsh L, Welsh M: VEGFA and tumour angiogenesis. J Intern Med 2013;273:114-127.

14 Byon JC, Kusari AB, Kusari J: Protein-tyrosine phosphatase-1B acts as a negative regulator of insulin signal transduction. Mol Cell Biochem 1998;182:101-108.

-15 Walchli S, Curchod ML, Gobert RP, Arkinstall S, Hooft van Huijsduijnen R: Identification of tyrosine phosphatases that dephosphorylate the insulin receptor. A brute force approach based on 'substratetrapping' mutants. J Biol Chem 2000;275:9792-9796.

-16 Salmeen A, Andersen JN, Myers MP, Tonks NK, Barford D: Molecular basis for the dephosphorylation of the activation segment of the insulin receptor by protein tyrosine phosphatase 1B. Mol Cell 2000;6:1401-1412.

$\checkmark 17$ Chavez JA, Summers SA: Characterizing the effects of saturated fatty acids on insulin signaling and ceramide and diacylglycerol accumulation in 3T3-L1 adipocytes and C2C12 myotubes. Arch Biochem Biophys 2003;419:101-109.

18 Dimopoulos N, Watson M, Sakamoto K, Hundal HS: Differential effects of palmitate and palmitoleate on insulin action and glucose utilization in rat L6 skeletal muscle cells. Biochem J 2006;399:473-481.

19 Hirabara SM, Curi R, Maechler P: Saturated fatty acid-induced insulin resistance is associated with mitochondrial dysfunction in skeletal muscle cells. J Cell Physiol 2010;222:187-194.

20 Powell DJ, Turban S, Gray A, Hajduch E, Hundal HS: Intracellular ceramide synthesis and protein kinase C $\zeta$ activation play an essential role in palmitate-induced insulin resistance in rat L6 skeletal muscle cells. Biochem J 2004;382:619-629.

-21 Sabin MA, Stewart CE, Crowne EC, Turner SJ, Hunt LP, Welsh GI, Grohmann MJ, Holly JM, Shield JP: Fatty acid-induced defects in insulin signalling, in myotubes derived from children, are related to ceramide production from palmitate rather than the accumulation of intramyocellular lipid. J Cell Physiol 2007;211:244-252.

22 Turpin SM, Lancaster GI, Darby I, Febbraio MA, Watt MJ: Apoptosis in skeletal muscle myotubes is induced by ceramides and is positively related to insulin resistance. Am J Physiol Endocrinol Metab 2006;291:E1341-E1350. 